\title{
The Pathologic Confirmation in Subepithelial Tumors
}

\author{
Kwan Hong Lee*, Chan Kyoo Yoo*, Hang Lak Lee, Kang Nyeong Lee, Dae Won Jun, Oh Young Lee, Dong Soo Han, Byung Chul Yoon, \\ Ho Soon Choi, Jai Hoon Yoon
}

Department of Internal Medicine, Hanyang University Hospital, Seoul, Korea

\begin{abstract}
Background/Aims: Subepithelial tumors (SETs) are small, mostly asymptomatic lesions with normal overlying mucosa, usually identified incidentally on endoscopy. The aim of this study was to evaluate the pathologic diagnosis of SETs, and to assess the diagnostic yield and impact of endoscopic submucosal dissection (ESD) biopsy on the management of patients with SETs.

Materials and Methods: We included 52 subepithelial lesions in this study during the study period. Inclusion criteria included size of the SET $>2 \mathrm{~cm}$, and a gastrointestinal stromal tumor (GIST) that cannot be excluded using EUS. We performed an endoscopic biopsy of each SET using the ESD technique.

Results: The mean diameter of the lesions was $24.15 \pm 6.0 \mathrm{~mm}$. The diagnostic yield of this method was $96.15 \%$. Among the 52 participants, 45 were located in the stomach, four in the esophagus, and three in the duodenum. The pathologic diagnoses included: 17 leiomyomas, 13 GISTs, 11 ectopic pancreases, two carcinomas, two inflammatory fibroid polyps, two Brunner's gland hyperplasia, two lipomas, one glomus tumor, and two remained undiagnosed. The mean duration of the procedure was $13.44 \pm 2.41$ minutes. Three complications were associated with the procedure.

Conclusions: Deep biopsy via ESD is useful in determining the histopathologic nature of SETs. This method minimizes the need for unnecessary surgery in benign SETs. (Korean J Helicobacter Up Gastrointest Res 2021;21:215-219)
\end{abstract}

Key Words: Endoscopic submucosal dissection biopsy; Pathology; Subepithelial tumor

\section{INTRODUCTION}

Subepithelial tumors (SETs) are occasionally found in the gastrointestinal tract during screening endoscopy. They have normal overlying mucosa and are usually asymptomatic. However, SETs do have malignant potential, and it is therefore important to distinguish malignant from benign lesions. Several management plans have been proposed for patients with gastric SETs. For example, the National Comprehensive Cancer Network has recommended that all gastrointestinal stromal tumors (GISTs) of $\geq 20 \mathrm{~mm}$ in size be resected owing to their management potential owing to their malignant potential. ${ }^{1}$ EUS can be used to preoperatively diagnose GISTs, although differential diagnosis on the basis of imaging alone is insufficient. ${ }^{2}$ EUS-guided fine needle aspiration (FNA) increases diag-

Received: December 24, 2020 Revised: January 30, 2021 Accepted: February 21, 2021 Corresponding author: Hang Lak Lee

Department of Internal Medicine, Hanyang University Hospital, 222-1 Wangsimni-ro, Seongdong-gu, Seoul 04763, Korea

Tel: +82-2-2290-8354, Fax: +82-2-2298-9183, E-mail: alwayshang@hanyang.ac.kr *Kwan Hong Lee and Chan Kyoo Yoo contributed equally to this work as first author This work was supported by the Korean College of Helicobacter and Upper Gastrointestinal Research Foundation Grant. nostic accuracy, but the results are quite variable. Lineartype EUS and EUS-FNA needles are needed for EUS-guided biopsy, and the technique has some limitations in small SET cases. ${ }^{3,4}$ Therefore, we performed endoscopic biopsies of SETs using the endoscopic submucosal dissection (ESD) technique. The aim of this study is to evaluate pathologic confirmation in patients with SETs. And we also evaluate the diagnostic yield and impact of an ESD biopsy technique on the clinical management of patients with SETs.

\section{MATERIALS AND METHODS}

A total of 52 patients (22 men, 30 women) who were scheduled to undergo EUS for gastric or duodenal SET between May 2010 and May 2015 were enrolled in the study. EUS images were examined for mass size, echogenicity, and invasion layer. All lesions eligible for participation based on EUS examination were $>2 \mathrm{~cm}$ in diameter and were well circumscribed masses originating in the muscularis propria, submucosa or muscularis mucosal layer of the stomach. All patients had a normal complete blood count and prothrombin time. The ethics committee

Copyright $\odot 2021$ Korean College of Helicobacter and Upper Gastrointestinal Research

@ The Korean Journal of Helicobacter and Upper Gastrointestinal Research is an Open-Access Journal. All articles are distributed under the terms of the Creative Commons Attribution Non-Commercial License (http:// creativecommons.org/licenses/by-nc/4.0) which permits unrestricted non-commercial use, distribution, and reproduction in any medium, provided the original work is properly cited. 


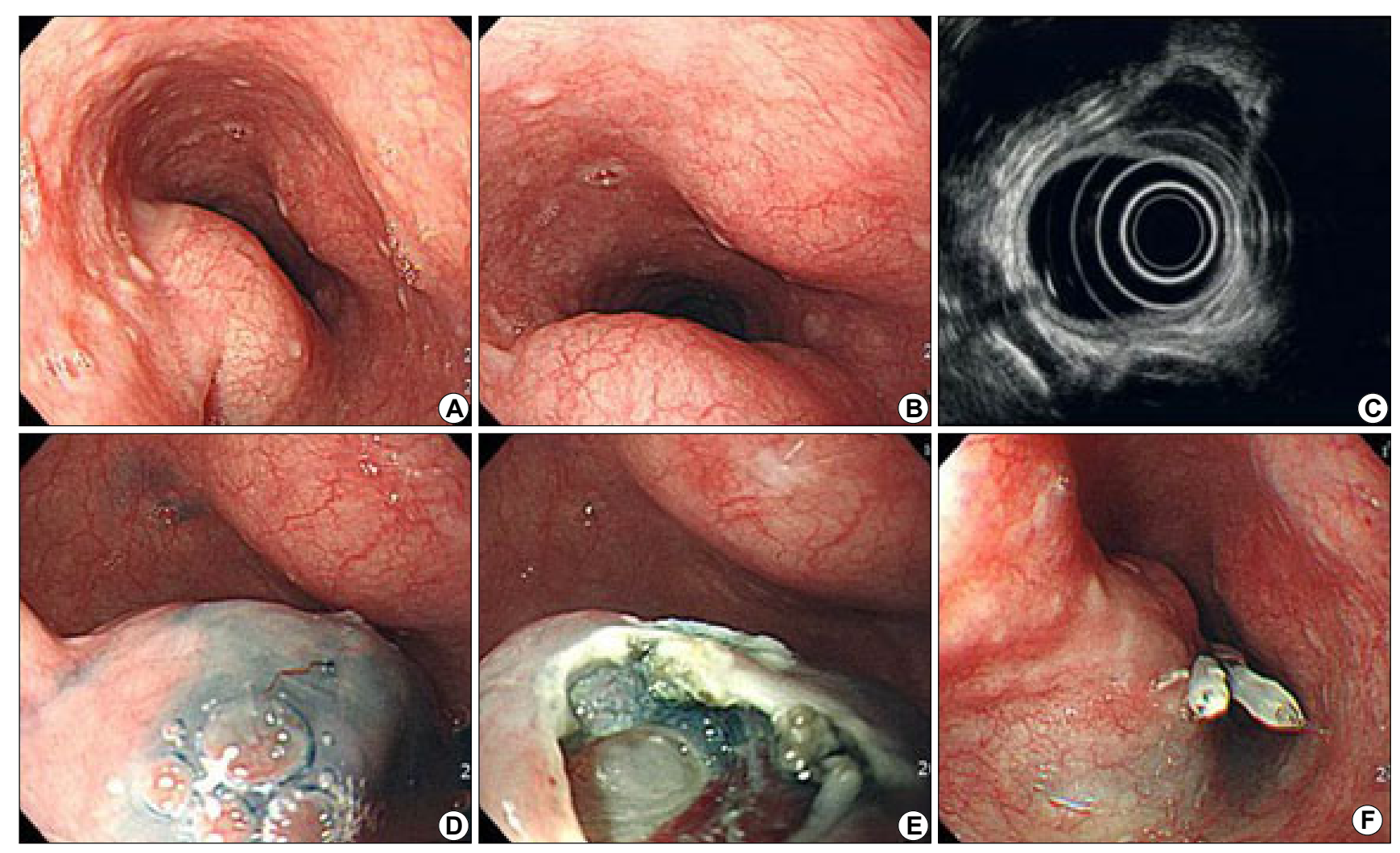

Fig. 1. Endoscopic biopsy of an esophageal subepithelial tumor. (A, B) Subepithelial tumor in the esophagus. (C) Hypoechoic mass in the fourth layer. (D) Injection of hypertonic saline solution. (E) After the mucosal and submucosal layers were removed. (F) Closure was achieved with clipping.

of hanyang university hospital approved the study protocol. Informed consent for the endoscopic procedure was obtained from each patient before the procedure.

Patients in whom a SET was identified during upper endoscopy and EUS were eligible to participate in this study. Endoscopic biopsy of SET was performed using a flex knife (Ji-In Corp, Ltd, Seoul, Korea), an IT 2-knife (Olympus, Tokyo, Japan), and a standard upper endoscope (GIF-H260; Olympus). All patients were given intravenous midazolam and pethidine before the procedure. All procedures were performed by one experienced endoscopist on an outpatient basis.

The ESD technique was performed as follows (Fig. 1). About $10 \mathrm{~mL}$ of epinephrine in hypertonic saline solution (dilution 1:1,000) was injected into the submucosa on the highest part of the lesion. Next, a 5-mm-diameter hole was created using a flex knife. Through this opening, the IT2-knife was introduced, and a round incision approximately $15 \mathrm{~mm}$ in diameter was made in the overlying mucosa using blend electrosurgical current. Then, sub- mucosal dissection was performed with the IT2-knife. When the round mass was uncovered beneath the submucosal layer, we performed endoscopic biopsies five to six times by using forceps (radial Jaws 3, $2.8 \mathrm{~mm}$ outer diameter; Boston Scientific, Inc., Natick, MA, USA). After the procedure, closure was achieved with clipping.

\section{RESULTS}

Endoscopic histologic diagnosis of SET after the ESD technique was performed in the 52 patients enrolled in the study. The mean age of the 52 patients was $52.03 \pm 13.35$ years, and 22 were male. The clinical, endoscopic, and EUS study results of the patients are summarized in Table 1 . The mean diameter of the SETs was $24.15 \pm 6.0 \mathrm{~mm}$. The diagnostic yield of this method was $96.15 \%$ (50/52). Of the 52 SETs, 45 were located in the stomach, four in the esophagus, and three in the duodenum. Their pathologic diagnoses were as follows: 17 leiomyomas, 13 GISTs, 11 ectopic pancreases, two 
Table 1. Baseline Characteristics of the Participants

\begin{tabular}{|c|c|}
\hline & Subepithelial tumors $(\mathrm{n}=52)$ \\
\hline Age (years) & $52.03 \pm 13.35(20-75)$ \\
\hline Sex, M/F & $22(42.3) / 30(57.7)$ \\
\hline \multicolumn{2}{|l|}{ Tumor location } \\
\hline Esophagus & $4(7.7)$ \\
\hline Stomach & $45(86.5)$ \\
\hline Fundus & $9(17.3)$ \\
\hline Cardia & $9(17.3)$ \\
\hline Body & $12(23.1)$ \\
\hline Antrum & $15(28.8)$ \\
\hline Duodenum & $3(5.8)$ \\
\hline \multicolumn{2}{|l|}{ EUS findings } \\
\hline Size (mm) & $24.15 \pm 6.0(20-40)$ \\
\hline \multicolumn{2}{|l|}{ Layer } \\
\hline 2nd/3rd/4th & $5(9.6) / 19(36.5) / 28(53.8)$ \\
\hline \multicolumn{2}{|l|}{ Echogenicity } \\
\hline Hypoechoic/hyperechoic/mixed & $41(78.8) / 2(3.8) / 9(17.3)$ \\
\hline \multicolumn{2}{|l|}{ Pathology } \\
\hline Leiomyoma & $17(32.7)$ \\
\hline GIST, low risk/moderate risk & $9(17.3) / 4(7.7)$ \\
\hline Ectopic pancreas & $11(21.2)$ \\
\hline Brunner's gland hyperplasia & $2(3.8)$ \\
\hline Inflammatory fibroid polyp & $2(3.8)$ \\
\hline Lipoma & $2(3.8)$ \\
\hline Adenocarcinoma & $1(1.9)$ \\
\hline Glomus tumor & $1(1.9)$ \\
\hline Lymphoepithelial carcinoma & $1(1.9)$ \\
\hline None made & $2(3.8)$ \\
\hline \multicolumn{2}{|l|}{ Prognosis } \\
\hline Follow up & $44(84.6)$ \\
\hline Operation & $8(15.4)$ \\
\hline Procedure time (minutes) & $13.44 \pm 2.41(8-45)$ \\
\hline \multicolumn{2}{|l|}{ Complication } \\
\hline Delayed bleeding & $1(1.9)$ \\
\hline Immediate bleeding & $1(1.9)$ \\
\hline Pneumomediastinum & $1(1.9)$ \\
\hline
\end{tabular}

Values are presented as mean \pm standard deviation (range) or number (\%).

M, male; F, female; EUS, endoscopic ultrasound; GIST, gastrointestinal stromal tumor.

carcinomas, two inflammatory fibroid polyps, two Brunner's gland hyperplasias, two lipomas, one glomus tumor, and two remained undiagnosed. When our cases divided into two categories (benign vs. malignant), only 16 cases were malignant or malignant related lesions. The mean procedure time was $13.44 \pm 2.41$ minutes. There were three complications associated with procedure. Pneumomediastium was developed after the procedure in one patient. However, it was improved after conservative treatment. Patient whose biopsy result was glomus tumor showed active major bleeding during procedure. Endoscopic hemostasis was performed without problem. One patient presented with hematemesis 2 days after the procedure. Work-up revealed minimal bleeding at the procedure site. The bleeding stopped naturally without further endoscopic hemostasis. Surgical resection was performed in eight cases and all other cases are during regular follow up.

\section{DISCUSSION}

The present study suggests that deep biopsy using the ESD technique can provide key information for management of upper gastrointestinal SETs. These data also demonstrate that this modality can be safely and conveniently used. All procedures were performed on an outpatient basis.

Due to the widespread availability of high-resolution endoscopy, submucosal tumors (SMTs) arising in the upper gastrointestinal tract are increasingly being identified. When a SMT is encountered during upper endoscopy, the difficulty encountered in formulating a management plan lies in the uncertainty of the histopathology of the tumor. ${ }^{5,6}$

Management plans for upper gastrointestinal SETs are determined using algorithms based on EUS images. ${ }^{7-9}$ EUS has long been believed to improve the diagnostic precision of SETs. However, EUS morphologic features alone have limited specificity for the subtypes of SETs. EUS-FNA and EUS-guided trucut biopsy (EUS-TCB) are currently routinely performed. EUS-FNA biopsies can obtain specimens from desired exact location using with EUS image, but its exclusive instruments, technical difficulty and complications (accidental perforations, etc.) are disadvantages. Also obtain tissue cores is limited. ${ }^{10}$ EUS-TCB biopsies have a higher diagnostic yield and can obtain tissue cores for immunohistochemical staining, but its efficacy is limited because of technical failure due to the stiffness of trucut 
needles. ${ }^{11,12}$ The diagnostic yield of EUS-TCB ranged from $55 \%$ to $79 \%$ and that of EUS-FNA varied from $52 \%$ to $82 \%{ }^{12}$ Furthermore, additional radial scopes, linear scopes, etc. are needed for EUS-FNA and fine-needle biopsy. These scopes and their accessories are expensive, however biopsy by using ESD can be performed with existing equipments. It is also difficult to obtain tissue samples using jumbo biopsy forceps and bite-on-bite techniques in SETs with normal overlying mucosa. Diagnostic yield of traditional unroofing biopsy of subepithelial lesions was $17 \sim 35 \% .^{13,14}$

In Korea, as of 10 years ago, medical checkup programs are available to the whole nation. Therefore, asymptomatic SETs are occasionally diagnosed during routine endoscopy. Until now, there were no reliable guidelines about the management of SETs. Management plans vary depending on the physician. In our study, a surgical resection was considered for all participants, according to the size of the SET and the EUS findings. However, our pathologic results showed that only 16 of the 52 total cases were malignant lesions, which included GIST, adenocarcinoma, and glomus tumor. The development of ESD techniques have resulted in many reports about the effectiveness of ESD in large SETs. ${ }^{15-17}$ The histopathologic results after ESD are mainly benign lesions such as leiomyoma or ectopic pancreas. Since the lesions that were thought to be SMT lesions were often different lesions, it is recommended revealing a pathological diagnosis before surgery.

In conclusion, our study suggests that histologic confirmation should be considered in upper gastrointestinal SETs before determining whether tumors should undergo long-term monitoring or surgical resection.

\section{CONFLICT OF INTEREST}

No potential conflict of interest relevant to this article was reported.

\section{ORCID}

Kwan Hong Lee (1) https://orcid.org/0000-0002-5264-388X

Chan Kyoo Yoo (10 https://orcid.org/0000-0001-5509-8779

Hang Lak Lee (1) https://orcid.org/0000-0002-2825-3216
Kang Nyeong Lee (1) https://orcid.org/0000-0002-3728-8672

Dae Won Jun (10 https://orcid.org/0000-0002-2875-6139

Oh Young Lee (1) https://orcid.org/0000-0002-6025-530X

Dong Soo Han (1) https://orcid.org/0000-0001-7103-3318

Byung Chul Yoon (1) https://orcid.org/0000-0002-4721-1927

Ho Soon Choi (1) https://orcid.org/0000-0003-3746-8742

Jai Hoon Yoon (10 https://orcid.org/0000-0003-3194-5149

\section{REFERENCES}

1. Demetri GD, Benjamin RS, Blanke CD, et al. NCCN Task Force report: management of patients with gastrointestinal stromal tumor (GIST)--update of the NCCN clinical practice guidelines. J Natl Compr Canc Netw 2007;5 Suppl 2:S1-29; quiz S30.

2. Hwang JH, Saunders MD, Rulyak SJ, Shaw S, Nietsch H, Kimmey MB. A prospective study comparing endoscopy and EUS in the evaluation of GI subepithelial masses. Gastrointest Endosc 2005;62:202-208.

3. Hoda KM, Rodriguez SA, Faigel DO. EUS-guided sampling of suspected GI stromal tumors. Gastrointest Endosc 2009;69: 1218-1223.

4. Fernández-Esparrach G, Sendino O, Solé M, et al. Endoscopic ultrasound-guided fine-needle aspiration and trucut biopsy in the diagnosis of gastric stromal tumors: a randomized crossover study. Endoscopy 2010;42:292-299.

5. Tae HJ, Lee HL, Lee KN, et al. Deep biopsy via endoscopic submucosal dissection in upper gastrointestinal subepithelial tumors: a prospective study. Endoscopy 2014;46:845-850.

6. Lee HL, Kwon OW, Lee KN, et al. Endoscopic histologic diagnosis of gastric GI submucosal tumors via the endoscopic submucosal dissection technique. Gastrointest Endosc 2011;74: 693-695.

7. Kang YK, Kang HJ, Kim KM, et al. Clinical practice guideline for accurate diagnosis and effective treatment of gastrointestinal stromal tumor in Korea. Cancer Res Treat 2012;44:85-96.

8. Hwang JH, Rulyak SD, Kimmey MB; American Gastroenterological Association Institute. American Gastroenterological Association Institute technical review on the management of gastric subepithelial masses. Gastroenterology 2006;130:22172228.

9. Eckardt AJ, Wassef W. Diagnosis of subepithelial tumors in the GI tract. Endoscopy, EUS, and histology: bronze, silver, and gold standard? Gastrointest Endosc 2005;62:209-212.

10. Ito $H$, Inoue $H$, Ryozawa $S$, et al. Fine-needle aspiration biopsy and endoscopic ultrasound for pretreatment pathological diagnosis of gastric gastrointestinal stromal tumors. Gastroenterol Res Pract 2012;2012:139083.

11. Obuch J, Wani S. EUS-guided tissue acquisition in GI stromal tumors. Gastrointest Endosc 2017;86:516-518.

12. Lee JH, Cho CJ, Park YS, et al. EUS-guided 22-gauge fine needle biopsy for the diagnosis of gastric subepithelial tumors larger 
than $2 \mathrm{~cm}$. Scand J Gastroenterol 2016;51:486-493.

13. Hedenbro JL, Ekelund M, Wetterberg P. Endoscopic diagnosis of submucosal gastric lesions. The results after routine endoscopy. Surg Endosc 1991;5:20-23.

14. Cantor MJ, Davila RE, Faigel DO. Yield of tissue sampling for subepithelial lesions evaluated by EUS: a comparison between forceps biopsies and endoscopic submucosal resection. Gastrointest Endosc 2006;64:29-34.

15. Li QL, Yao LQ, Zhou PH, et al. Submucosal tumors of the esophagogastric junction originating from the muscularis propria layer: a large study of endoscopic submucosal dissection (with video). Gastrointest Endosc 2012;75:1153-1158.

16. Shi Q, Zhong YS, Yao LQ, Zhou PH, Xu MD, Wang P. Endoscopic submucosal dissection for treatment of esophageal submucosal tumors originating from the muscularis propria layer. Gastrointest Endosc 2011;74:1194-1200.

17. He Z, Sun C, Wang J, et al. Efficacy and safety of endoscopic submucosal dissection in treating gastric subepithelial tumors originating in the muscularis propria layer: a single-center study of 144 cases. Scand J Gastroenterol 2013;48:1466-1473. 